\title{
Gut microbiota and colorectal cancer
}

\author{
Mayuko Yamamoto ${ }^{*}$ and Satoshi Matsumoto
}

\begin{abstract}
The mucosal immune system is unique to the gastrointestinal mucosa, in which a large number of immune cells are located and exert multiple functions. Meanwhile, 100 trillion microorganisms are thought to co-inhabit in the gastrointestinal tract. Furthermore, immune cells and gut microbiota have a mutual influence and the maintenance of this symbiotic relationship results in gut homeostasis. A recent study suggested that a disturbance of gut microbiota — so called "dysbiosis" —is related to various diseases, such as inflammatory bowel disease (IBD) and colitis-associated cancer (CAC). In this review, we discuss the relationship between gut microbiota and the mucosal immune system with regard to the development of IBD and CAC. In addition, we elucidate the possibility of probiotics in treatment against these diseases.
\end{abstract}

Keywords: Gut microbiota, Colorectal cancer, Colitis-associated cancer, Mucosal immune system, Dysbiosis

\section{Background}

The mammalian gastrointestinal tract, where digestion and absorption occurs, acts as the frontline of defense against microorganisms from the environment. Therefore there is an established unique immune surveillance system called the mucosal immune system. It is supposed that a half of immunocompetent cells reside in the gut mucosa, and the balance between them with a variety of properties, including $\mathrm{T}$ helper 17 (Th17) cells and regulatory $\mathrm{T}\left(\mathrm{T}_{\text {reg }}\right)$ cells, is thought to be controlled exquisitely. Characteristics of the mucosal immune system are represented by their contrasted immune functions, such as the removal of pathogens and immune unresponsiveness to the food antigens and indigenous gut microbiota. Increasing evidence suggests that the gut microbiota also plays key roles in homeostatic maintenance of the mucosal immune system. Imbalance of gut microbiota, so called "dysbiosis", based on dysregulation of the mucosal immune system affects the development and pathogenesis of various diseases such as allergy, diabetes, autoimmune diseases and cancer $[1,2]$. In addition, a recent finding has suggested that when feces of healthy adults were intra-rectally inoculated into patients with recurrent Clostridium difficile infection, the symptoms improved in association with the recovery from dysbiosis [3], which would be a clear example of gut microbiota contributing to restraint of colonic

\footnotetext{
* Correspondence: mayuko-yamamoto@yakult.co.jp

Yakult Central Institute, 5-11 Izumi, Kunitachi-shi, Tokyo 186-8650, Japan
}

inflammation. Furthermore regarding the onset of inflammatory bowel disease (IBD) and colitis-associated cancer (CAC), the interaction between the mucosal immune system and gut microbiota is important, because in germfree animal models of these diseases, no symptoms are observed $[4,5]$. In this review, we discuss the roles of gut microbiota and the mucosal immune system on the development of IBD and CAC.

\section{Review \\ Gut microbiota in IBD}

IBD is categorized into Crohn's disease (CD) and ulcerative colitis (UC) based on pathophysiological characteristics. UC is an inflammatory disease confined to the colonic mucosa, whereas $\mathrm{CD}$ has the potential to develop along the entire gastrointestinal tract with a higher occurrence in the small and large intestines. Because both diseases exhibit repeated remission and relapse, it is important that we urgently improve the quality of life of patients with IBD. In accordance with the development of an analytical method, based on bacterial $16 \mathrm{~S}$ rDNA and next generation sequencing (NGS), the characteristics of gut microbiota in patients with IBD are rapidly being elucidated. A loss of bacterial diversity and dysbiosis is present in the gut microbiota of patients with IBD, as commonly detected using NGS. In particular, there is a marked decrease in the occupancy of Firmicutes and Bacteroidetes in gut microbiota, which normally predominates in a healthy adult. It has been 
reported that 46 strains of Clostridium derived from mice and 17 strains of Clostridium derived from humans induced differentiation of Foxp $3^{+} \mathrm{T}_{\text {reg }}$ cells, resulting in mass production of IL-10, via augmentation of TGF- $\beta$ provided by colonic epithelial cells $[6,7]$. It was then demonstrated that Clostridium butyricum when used as a probiotic, could induce IL-10 production from macrophages in colonic mucosa, which resulted in suppression of acute colitis in mice [8]. It has been discussed that butyrate participated in suppression of colitis and colorectal cancer. The bacterial metabolite, butyrate, induces the differentiation of colonic Foxp $3^{+} \mathrm{T}_{\text {reg }}$ cells and ameliorates the development of colitis. A possible mechanism for this regulation of differentiation may be that butyrate enhances histone $\mathrm{H} 3$ acetylation in the promoter and conserved, non-coding sequence regions of the Foxp3 locus [9]. Because the occupancy of Clostridium clusters IV and XIVa, in which numerous butyrateproducing bacteria exist, have been shown to be decreased in the gut microbiota of patients with IBD, it would be expected that clinical applications of these results would follow.

With regard to the interaction of the mucosal immune system and gut microbiota, secretory immunoglobulin A (IgA) is important. The presence of secretory IgA in the intestinal lumen is indispensable for the exclusion of pathogenic germs and neutralization of toxins. Germfree mice have few IgA-producing cells in their intestinal mucosa. Total bacterial numbers increase markedly in the mice deleted activation induced cytidine deaminase (AID) gene, which is normally essential for somatic hypermutation and class switch recombination during IgA gene rearrangement. IgA produced in inhibitory receptor of immune system (programmed cell death-1 (PD-1)) gene-deficient mice had a low affinity for bacteria, which caused alterations of microbial communities in the gut [10]. In addition, it has been recently reported that some gut microbiota was coated with IgA, and IgAcoated fecal bacteria taken from patients with IBD exacerbated dextran sulfate sodium (DSS)-induced colitis in gnotobiotic mice [11].

\section{Gut microbiota in colorectal cancer}

Colorectal cancer is one of the most common fatal malignancies in the world. The involvement of gut microbiota in the development of colorectal cancer has been noted for some time. IL-10-deficient mice and TCR $\beta$ / p53 double knockout mice do not develop colorectal cancer under germfree environment, providing a rationale for the association between colorectal cancer and gut microbiota [12]. Chronic inflammation is known to predispose an individual to cancer, and as such, the presence of IBD increases the risk of colorectal cancer. Another such example would be CAC. The molecular mechanisms underlying the pathogenesis of CAC are unclear and do not follow the adenoma-carcinoma sequence [13]. It is urgent to clarify the mechanism underlying development of CAC, because $\sim 20 \%$ of patients with chronic inflammation in the form of UC develop CAC within 30 years from the onset, with at least half of the cases resulting in death. A recent study demonstrated that dysbiosis of gut micobiota plays a key role in the pathophysiology of CAC. Bacterial diversity is remarkably decreased in gut microbiota of sporadic colorectal cancer and CAC mice models. When gnotobiotic mice are colonized with feces taken from sporadic colorectal cancer or CAC mice, the incidence and number of tumors are increased in both cases, compared with those colonized with feces of healthy mice. CAC can be experimentally induced in rodent models by the combination of introduction to azoxymethane (AOM) and repeated exposure to the inflammatory agent DSS. Results from time-course analysis of the composition of gut microbiota during development of CAC in this model indicated tumor-bearing mice showed enrichment in operational taxonomic units (OTUs) affiliated with members of the Bacteroides, Odoribacter, and Allobaculum genera and decreases in OTUs affiliated with members of the Prevotellaceae and Porphyromonadaceae families. Furthermore, conventionalization (colonization of germfree mice with gut microbiota) with tumor-bearing mice significantly increased colon tumorigenesis compared to those colonized with feces of healthy mice [14]. However, mice exposed to the chemical mutagen do not develop tumors if they receive antibiotics and mice that received feces of tumor-bearing mice do not develop tumors if they are not exposed to the mutagen. These findings suggest that gut microbiota plays a part in the initiation of colorectal cancer. CAC results from the complex relationship between chronic inflammation and dysbiosis of gut microbiota, which would induce irreversible changes to intestinal epithelial cells. Bacteroides fragilis toxin, produced by enterotoxigenic B. fragilis (ETBF), triggers colorectal cancer by binding to colonic epithelial cells and stimulating cleavage of the cell adhesion molecule E-cadherin, which act as the tumor suppressor protein [15]. Antibody-mediated blockade of interleukin-17 (IL-17), a key cytokine for proinflammatory responses, inhibits ETBF-induced colitis and tumor formation [16]. Gut microbiota of IL-10 deficient mice developing spontaneously severe colitis have decreases in bacterial diversity and increases in the occupancy of Enterobacteriaceae [17]. IL-10 deficient mice colonized with either Escherichia coli (E. coli) or Enterococcus faecalis develop colon inflammation, but only the mice receiving $E$. coli developed colon tumors. Moreover, it was reported that Colibactin, the product of polyketide synthase (pks) in E. coli NC101, 
cleaved double stranded DNA in colonic epithelial cells and promoted invasive carcinoma in AOM-treated IL10deficient mice [18]. Because the expression of the ETBF toxin gene and pks gene of E. coli NC101 is higher in patients with colorectal cancer when compared to healthy adults, aberrant proliferation of these bacteria caused by dysbiosis of gut microbiota would induce disruption of epithelial barrier function and contribute to the mechanism of CAC development. However, there is some uncertainty, because the murine AOM/DSS model administered microbes from patients with colorectal cancer developed unexpectedly fewer tumors than those that received bacteria from healthy human donors [19]. Therefore, we would need to validate the evidence, accumulated by studies using animal models of colorectal cancer, in human. Furthermore, it has also been revealed that the role of gut microbiota in cancer extended to treatment, influencing not only the effectiveness of chemotherapy but also its side effects. Both germfree mice and antibiotic-treated mice show cyclophosphamide resistance and in these mice, pathogenic Th17 cells are shown to be decreased [20]. Taken together, it is likely that modulating the gut microbiota will become an effective tool to combat colorectal cancer.

\section{CAC and IL-6/Stat3 pathway}

The mucosal activation of the IL-6/signal transducer and activator of transcription 3 (Stat3) pathway is important for the pathogenesis of IBD and CAC. The inflammatory cytokine IL-6 shows multiple functions and modulates various physiological and immune responses. IL- 6 exerts its biological action by binding to two types of membrane receptors, specifically the IL- 6 receptor alpha subunit (IL-6R $\alpha)$ and gp130. IL-6 binds to IL-6R $\alpha$ at the cell membrane of target cells and this complex in turn associates with gp130, inducing signal transduction via phosphorylation of Stat3. IL-6R $\alpha$ is expressed on specific cells, such as neutrophils, macrophages, hepatocytes, and several lymphocyte subsets, whereas gp130 is expressed on the cell surface of various cell types. Through this mechanism, the canonical IL-6 signal can transmit their signal to limited cells, which express the IL-6R $\alpha$. Suppressor of cytokine signaling 3 (SOCS3) is IL-6/Stat3 responsive protein which inhibits phosphorylation of Stat3 by binding to Janus kinase (JAK) and negatively regulates IL-6-induced signaling. In patients with $\mathrm{CD}$ and in murine models of CD (SAMP1/Yit), expression of IL-6 and SOCS3 in the gut is enhanced and Stat3 is excessively phosphorylated [21]. It was also reported that there is an increase in the serum levels of soluble form of IL-6R $\alpha$ (sIL-6R $\alpha)$ under inflammatory conditions. sIL-6R $\alpha$ is produced either by TNF $\alpha$ converting enzyme (TACE), which proteolytically cleaves extracellular domain of membrane-bound IL-6R $\alpha$, or by the differential splicing of IL-6R $\alpha$ mRNA. IL- 6 shows an affinity to sIL-6Rs, forming the IL-6/sIL-6R $\alpha$ complex that can interact with gp130 and induce IL-6 signal transduction, termed IL-6 trans-signaling. IL-6 transsignaling can transmit the IL- 6 signal in the cells that express only gp130 and promote an inflammatory response through phosphorylation of Stat3. Because the expression of gp130 is ubiquitous, there is a non-specific enhancement of IL-6 trans-signaling is thought to be an enhancer of canonical IL- 6 signal pathway. The importance of IL-6 trans-signaling in the etiology of several chronic inflammations, such as asthma, colitis, and rheumatoid arthritis, has been well documented [22-24]. We previously revealed that the activation of IL-6/Stat3 pathway via IL-6 trans-signaling plays a crucial role in the development of ileitis in SAMP1/Yit mice and murine CAC models [25]. We induced CAC in BALB/c mice by administering 9 cycles of treatment with 4-5\% DSS in drinking water for 7 days and normal drinking water for 7 days. CAC was microscopically observed in $>60$ $80 \%$ of mice after DSS treatment. Histologically, we observed the proliferation of gland epithelial cells, resulting in the formation of a polypoid mass (Fig. 2a). Our hypothesis of the association between IL-6 trans-signaling and inflammation-based colon tumorigenesis is shown in Fig. 1. IL-6 trans-signaling triggered in LP inputs its downstream signal into intestinal epithelial cells (IECs) and induces the expression of anti-apoptotic gene and AID and the production of reactive oxygen species (ROS), which leads to the inhibition of cell death, genetic instability and DNA damage. Mice which are deficient in both IL-10 and AID do not develop colon cancer, whereas IL-10-deficient mice develop spontaneous colon cancers [26]. Aberrant AID expression in the inflamed colonic mucosa plays an integral role during the development of CAC via accumulation of genetic aberrations. Therefore it is speculated that long-term accumulation of IL-6 trans-signaling finally leads to colon tumorigenesis. Interestingly, the expression of IL-6, TACE and phospho-Stat3 in CAC mucosa was higher than those in the colitis mucosa (Fig. 2b). Soluble gp130Fc (sgp130Fc) is a dimerized fusion protein of gp130 that competitively suppresses the activation of IL6 trans-signaling by preventing the interaction between gp130 and the IL-6/sIL-6R $\alpha$ complex. Treatment of DSS-induced CAC model with sgp130Fc suppressed the expression of phospho-Stat 3 and the incidence and number of tumors were reduced, compared with vehicle-treated mice (Fig. 2c). Consequently, it was revealed that the activation of IL-6 trans-signaling in colonic mucosa was essential for triggering CAC. In our previous study, we indicated that the main source supplying IL-6 in the development of CAC was 


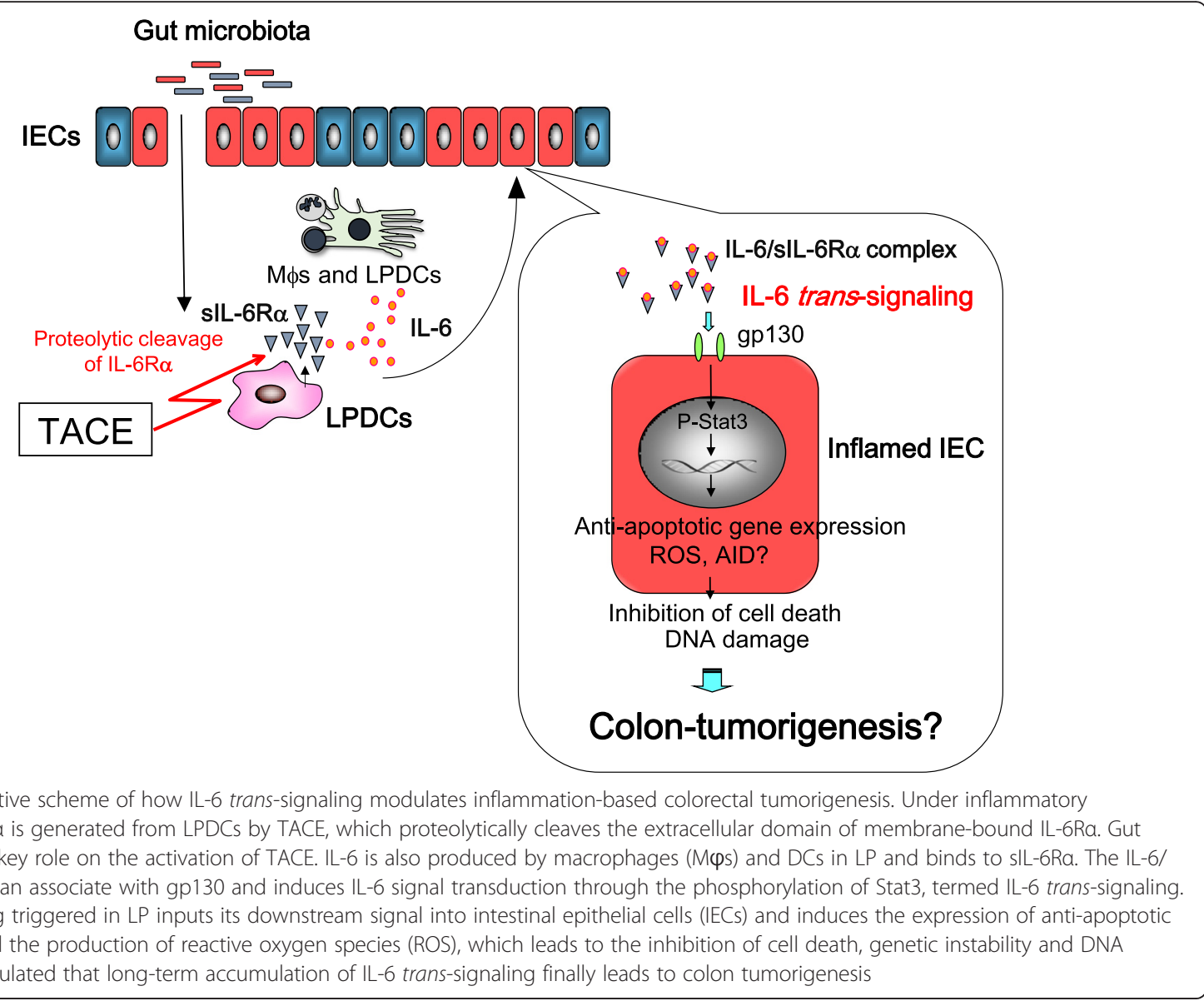

macrophages and dendritic cells (DCs) located in colonic lamina propria (LP). Moreover, it became clear that a distinct subpopulation of LPDCs was the main sources of sIL-6R $\alpha$. LP macrophages, purified from mice with ongoing chronic colitis, actively cleaved sIL-6R $\alpha$ into the culture supernatant after stimulation with heat-killed commensal bacteria ex vivo. However the presence of a TACE inhibitor markedly reduced this cleavage. This result indicates that gut microbiota participated in the production of sIL-6R $\alpha$ in colonic LP macrophage through TACE activation. Interestingly, the expression of membrane-bound IL-6R $\alpha$ was markedly decreased in epithelial cells of chronic colitis and CAC. In contrast, the expression of gp130 was significantly increased in epithelial cells of CAC. Therefore epithelial cells of chronic colitis and CAC are thought to be in a state more suitable for the receiving of IL-6 trans-signaling than the canonical IL-6 signal pathway.

\section{Probiotics as prevention for IBD/CAC}

Reverting the disturbances of gut microbiota in patients with IBD and CAC, as previously mentioned, should become the new strategy for treatment. Although several clinical trials using probiotics for patients with IBD have been performed in Japan and overseas, the clinical effects are dependent on the probiotic strain and the schedule of probiotic administration. In the trial for the patients with mildly to moderately active UC received one of the probiotic Lactobacillus strains, Lactobacillus casei strain Shirota (LcS), daily for 8 weeks, significantly better clinical activity index scores were seen after LcS treatment compared with pre-treatment and control group values [27]. In the trial for people at high-risk of developing colorectal cancer, they were administered wheat bran, LcS, both or neither. Incidence of tumors with a grade of moderate or high atypia was significantly lower in the group administered LcS than the other groups. No significant difference in the development of new colorectal tumors was observed with administration of either wheat bran or LcS [28]. After 1 year of treatment with Bifidobacterium breve strain Yakult and galacto-oligosaccharides symbiotics, the clinical status was significantly improved, and the amount of myeloperoxidase in the lavage, the number of Bacteroidaceae in feces and fecal $\mathrm{pH}$ was reduced in the patients with mild to moderate UC [29]. We had reported previously that LcS has the protective efficacy against CAC [30]. LcS suppressed the development of CAC by suppressing 
a
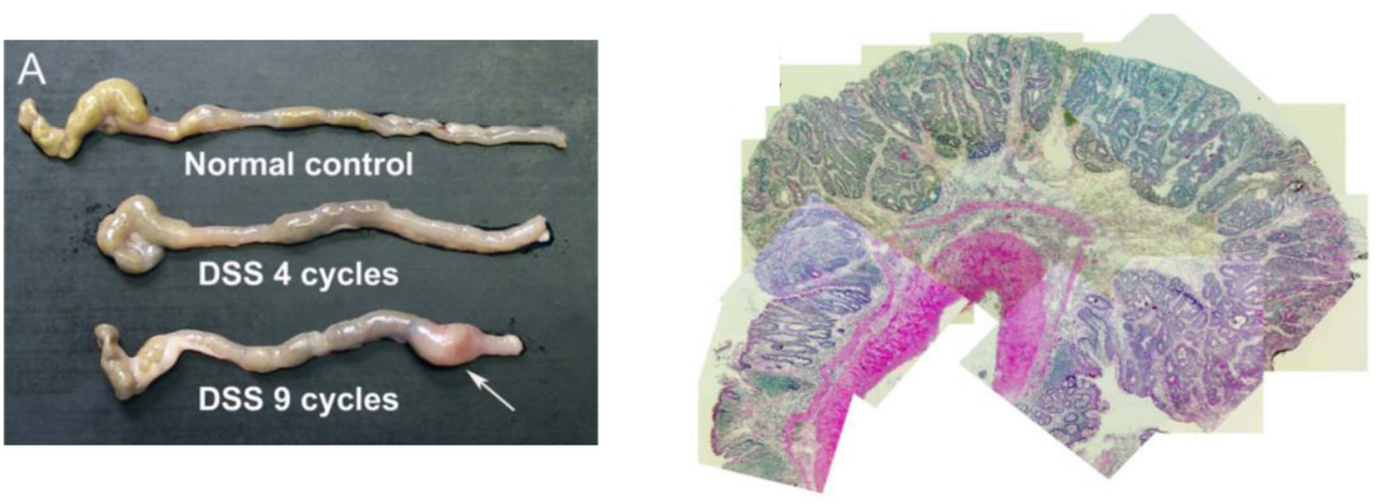

b
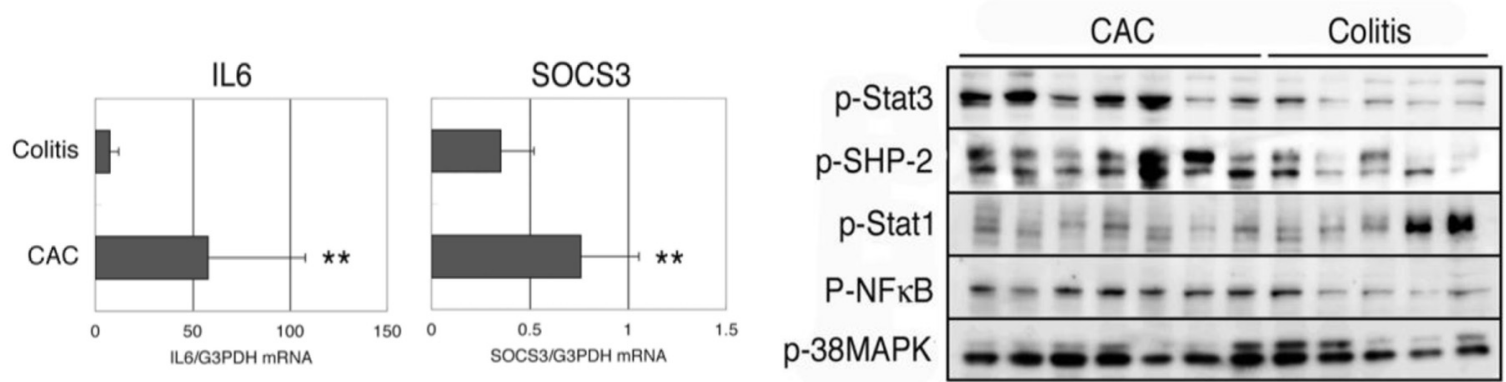

C
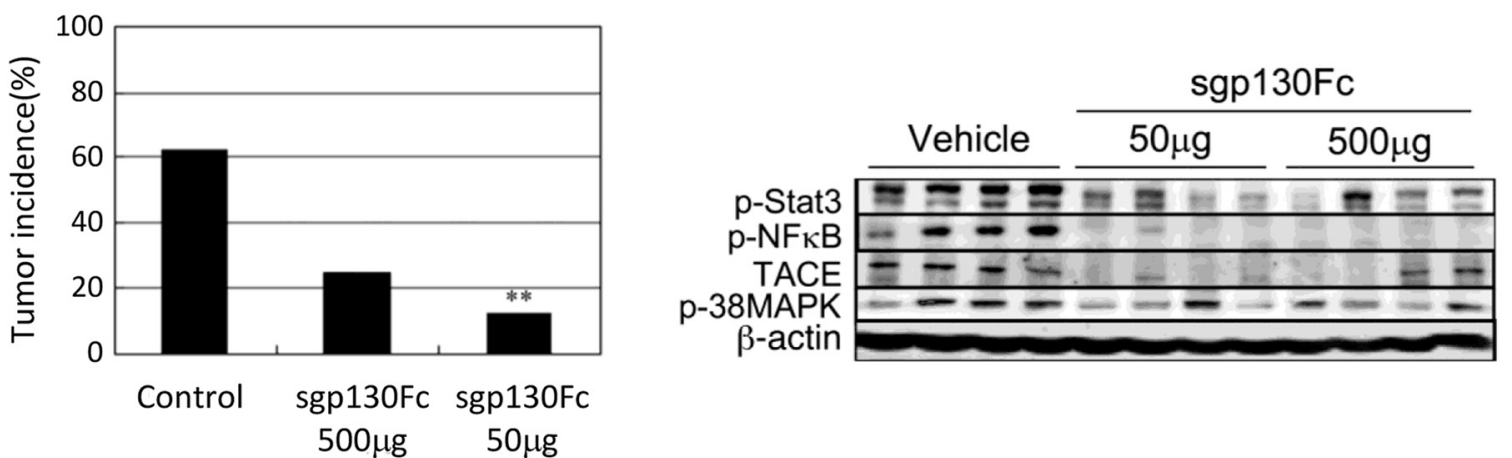

d
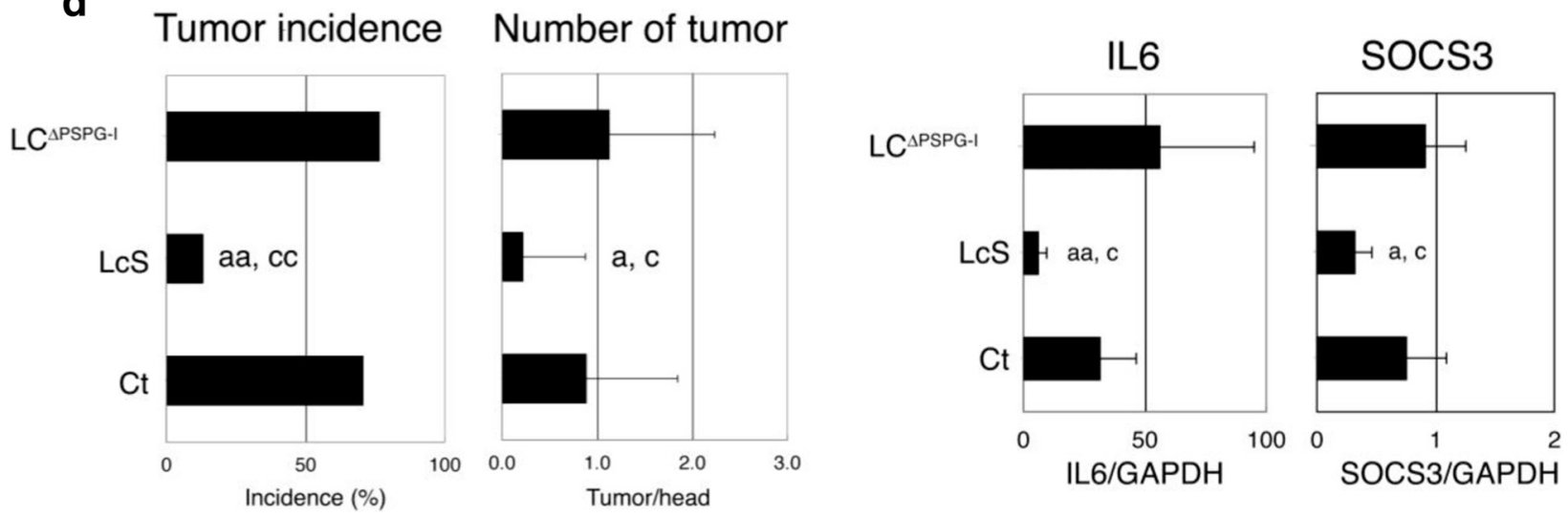

Fig. 2 (See legend on next page.) 


\section{(See figure on previous page.)}

Fig. 2 Characteristics of a murine model of CAC and the possibility of probiotic treatment in the prevention of CAC. A-left, Stereomicroscopic observation of a murine model of DSS-induced CAC. CAC was induced in BALB/C mice by nine cycles of treatment with 4-5\% DSS in drinking water for 7 days and normal drinking water for 7 days. The arrow indicates CAC. a-right, Histology of CAC. CAC tissue was fixed and stained with H\&E. B-left, Expression of IL-6 and SOCS3 mRNA. Total RNA was isolated from colon tissues of chronic colitis or CAC mice. Quantitative RT-PCR was performed using specific primer sets. The data are represented as the mean $\pm \mathrm{SD}(n=10)$. b-right, Expression of phosphorylated transcription factors in the mucosa of colitis or CAC mucosa. Colonic tissue homogenates were subjected to Western blotting with polyclonal antibodies against phospho-Stat3, phospho-SHP-2, phospho-Stat1, phospho-NFKB and phospho-38MAPK. C-left, Incidence of CAC. During the induction of CAC, sgp130Fc (500 or $50 \mu \mathrm{g} / \mathrm{mouse}$ ) or vehicle was injected i.p. into BALB/c mice on the first day of each 6-9 DSS cycle $(n=10)$ ). c-right, Western blot analysis of phospho-Stat3, phospho-NFKB, TACE, phospho-38MAPK and $\beta$-catenin in colonic tissue of sgp130Fc- or vehicle- treated mice. Dleft, Incidence and number of CAC. During CAC induction, the mice were treated with LCS, PS-PG1-deficient LCS (LC $\left.{ }^{\triangle P S-P G 1}\right)$ or Saline orally (5 days per week). d-right, Quantitative RT-PCR analysis of IL-6 and SOCS3 mRNA in colonic tissues in CAC-induced mice treated with LCS, LC ${ }^{\triangle P S-P G 1}$, or PBS. ${ }^{*}: p<0.05,{ }^{* *} ; p<0.01, a ; p<0.05$, aa; $p<0.01 \mathrm{LCS}$ versus $C t, c ; p<0.05, c c ; p<0.01 \mathrm{LCS}$ versus $L C^{\Delta P-S P G 1}$

IL-6 trans-signaling in a murine CAC model, whereas polysaccharide-peptidoglycan complex 1 (PS-PG1) deficient LcS strain had no effect on the prevention of CAC (Fig. 2d). It was also revealed that this effect of $\mathrm{LcS}$ was accompanied with improvement of dysbiosis of gut microbiota. As recently reported, transplant of fecal microbiota from healthy individuals is effective in treatment. However transplant of feces requires considered attention in patients with benign disorders, such as IBD, because there is a possibility of accidental contamination with unknown infectious diseases. By avoiding this, probiotics have guaranteed safeguards against such events. Therefore amelioration of dysbiosis by using probiotics could be a potent tool implemented as a new medical treatment for these diseases as well as their prevention.

\section{Conclusion}

Gastrointestinal mucosa has a unique immune system, in which many immune cells reside and exert multiple functions. Those immune cells and gut microbiota have a mutual influence on immune response. Recent studies suggested that an imbalance of gut microbiota- "dysbiosi$\mathrm{s}$ "-is related to the condition of patients with not only gastrointestinal diseases but also other diseases. It is estimated that dysbiosis of gut microbiota plays an essential role in the initiation of IBD and CAC. The strategy of recent studies on IBD and CAC is altering, which aimed at remedying dysbiosis by considering gut microbiota as "a microbial community effect" from studies focused on individual enterobacterial roles. Dysbiosis of gut microbiota presumably induces the change in the enteric environment that leads to mucosal inflammation or tumorigenesis. It will be necessary to accumulate a scientific overview for the interaction of gut microbiota and the mucosal immune system in the future, to utilize the improvement of the gut microbiota as a mode of treatment in the development of new cures for IBD and CAC.

\section{Abbreviations}

AID: activation induced cytidine deaminase; AOM: azoxymethane; CAC: colitis-associated cancer; CD: Crohn's disease; DC: dendritic cell; DSS: dextran sulphate sodium; ETBF: enterotoxigenic Bacteroides fragilis;
GOS: galacto-oligosaccharide; IBD: inflammatory bowel disease; IEC: intestinal epithelial cell; JAK: Janus kinase; LCS: Lactobacillus casei strain Shirota; LP: lamina propria; OTU: operational taxonomic units; PD-1: programmed cell death-1; pks: polyketide synthase; PS-PG1: polysaccharide-peptidoglycan complex 1; SOCS3: suppressor of cytokine signaling 3; Stat3: signal transducer and activator of transcription 3; TACE: TNFa converting enzyme; TLR: Toll-like receptor; UC: ulcerative colitis.

\section{Competing interests}

The authors declare that they have no competing interests.

\section{Authors' contributions}

Both authors made an equal contribution in preparation of manuscript. Both authors read and approved the final manuscript.

\section{Acknowledgement}

We would like to thank Dr Stefan Rose-John and Dr Keiichi Mitsuyama for their valuable support on this manuscript.

Received: 21 January 2016 Accepted: 29 March 2016

Published online: 01 June 2016

\section{References}

1. Schwabe RF, Jobin C. The microbiome and cancer. Nat Rev Cancer. 2013;13(11):800-12.

2. Sekirov I, Russell SL, Antunes LC, Finlay BB. Gut microbiota in health and disease. Physiol Rev. 2010;90(3):859-904.

3. van Nood E, Vrieze A, Nieuwdorp M, Fuentes S, Zoetendal EG, de Vos WM, Visser CE, Kuijper EJ, Bartelsman JF, Tijssen JG, Speelman P, Dijkgraaf MG, Keller JJ. Duodenal infusion of donor feces for recurrent Clostridium difficile. N Engl J Med. 2013;368(5):407-15.

4. Vetrano S, Danese S. Colitis, microbiota, and colon cancer: an infernal triangle. Gastroenterology. 2013;144(2):461-3.

5. DeWeerdt S. Microbiome: microbial mystery. Nature. 2015;521(7551):S10-1.

6. Atarashi K, Tanoue T, Shima T, Imaoka A, Kuwahara T, Momose Y, Cheng G, Yamasaki S, Saito T, Ohba Y, Taniguchi T, Takeda K, Hori S, Ivanov II, Umesaki $Y$, Itoh K, Honda K. Induction of colonic regulatory T cells by indigenous Clostridium species. Science. 2011;331(6015):337-41.

7. Atarashi K, Tanoue T, Oshima K, Suda W, Nagano Y, Nishikawa H, Fukuda S, Saito T, Narushima S, Hase K, Kim S, Fritz JV, Wilmes P, Ueha S, Matsushima K, Ohno H, Olle B, Sakaguchi S, Taniquchi T, Morita H, Hattori M, Honda K. Treg induction by a rationally selected mixture of Clostridia strains from the human microbiota. Nature. 2013;500(7461):232-6.

8. Hayashi A, Sato T, Kamada N, Mikami Y, Matsuoka K, Hisamatsu T, Hibi T, Roers A, Yagita H, Ohteki T, Yoshimura A, Kanai T. A single strain of Clostridium butyricum induces intestinal IL-10-producing macrophages to suppress acute experimental colitis in mice. Cell Host Microbe. 2013;13(6):711-22.

9. Furusawa Y, Obata Y, Fukuda S, Endo TA, Nakato G, Takahashi D, Nakanishi Y, Uetake C, Kato K, Kato T, Takahashi M, Fukuda NN, Murakami S, Miyauchi E, Hino S, Atarashi K, Onawa S, Fujimura Y, Lockett T, Clarke JM, Topping DL, Tomita M, Hori S, Ohara O, Morita T, Koseki H, Kikuchi J, Honda K, Hase K, Ohno H. Commensal microbe-derived butyrate induces the differentiation of colonic regulatory T cells. Nature. 2013;504(7480):446-50. 
10. Kawamoto S, Tran TH, Maruya M, Suzuki K, Doi Y, Tsutsui $Y$, Kato LM, Fagarasan S. The inhibitory receptor PD-1 regulates IgA selection and bacterial composition in the gut. Science. 2012;336(6080):485-9.

11. Palm NW, de Zoete MR, Cullen TW, Barry NA, Stefanowski J, Hao L, Degnan $\mathrm{PH}, \mathrm{Hu}$ J, Peter I, Zhang W, Ruggiero E, Cho JH, Goodman AL, Flavell RA. Immunoglobulin A coating identifies colitogenic bacteria in inflammatory bowel disease. Cell. 2014;158(5):1000-10.

12. Kado S, Uchida K, Funabashi H, Iwata S, Nagata $Y$, Ando M, Onoue M, Matsuoka Y, Ohwaki M, Morotomi M. Intestinal microflora are necessary for development of spontaneous adenocarcinoma of the large intestine in Tcell receptor beta chain and p53 double-knockout mice. Cancer Res. 2001;61(6):2395-8.

13. Saleh M, Trinchieri G. Innate immune mechanisms of colitis and colitisassociated colorectal cancer. Nat Rev Immunol. 2011;11:9-20.

14. Zackular JP, Baxter NT, Iverson KD, Sadler WD, Petrosino JF, Chen GY, Schloss PD. The gut microbiome modulates colon tumorigenesis. MBio. 2013;4(6):e00692-13.

15. Rhee KJ, Wu S, Wu X, Huso DL, Karim B, Franco AA, Rabizadeh S, Golub JE, Mathews LE, Shin J, Sartor RB, Golenbock D, Hamad AR, Gan CM, Housseau $F$, Sears CL. Induction of persistent colitis by a human commensal, enterotoxigenic Bacteroides fragilis, in wild-type C57BL/6 mice. Infect Immun. 2009;77(4):1708-18.

16. Wu S, Rhee KJ, Albesiano E, Rabizadeh S, Wu X, Yen HR, Huso DL, Brancati FL, Wick E, McAllister F, Housseau F, Pardoll DM, Sears CL. A human colonic commensal promotes colon tumorigenesis via activation of $\mathrm{T}$ helper type 17 T cell responses. Nat Med. 2009;15(9):1016-22.

17. Arthur JC, Perez-Chanona E, Mühlbauer M, Tomkovich S, Uronis JM, Fan TJ, Campbell BJ, Abujamel T, Dogan B, Rogers AB, Rhodes JM, Stintzi A, Simpson KW, Hansen JJ, Keku TO, Fodor AA, Jobin C. Intestinal inflammation targets cancer-inducing activity of the microbiota. Science. 2012;338(6103):120-3.

18. Arthur JC, Gharaibeh RZ, Mühlbauer M, Perez-Chanona E, Uronis JM, McCafferty J, Fodor AA, Jobin C. Microbial genomic analysis reveals the essential role of inflammation in bacteria-induced colorectal cancer. Nat Commun. 2014:5:4724.

19. Baxter NT, Zackular JP, Chen GY, Schloss PD. Structure of the gut microbiome following colonization with human feces determines colonic tumor burden. Microbiome. 2014;2:20.

20. Viaud S, Saccheri F, Mignot G, Yamazaki T, Daillère R, Hannani D, Enot DP, Pfirschke C, Engblom C, Pittet MJ, Schlitzer A, Ginhoux F, Apetoh L, Chachaty E, Woerther PL, Eberl G, Bérard M, Ecobichon C, Clermont D, Bizet C, Gaboriau-Routhiau V, Cerf-Bensussan N, Opolon P, Yessaad N, Vivier E, Ryffel B, Elson CO, Doré J, Kroemer G, Lepage P, Boneca IG, Ghiringhelli F, Zitvogel $\mathrm{L}$. The intestinal microbiota modulates the anticancer immune effects of cyclophosphamide. Science. 2013;342(6161):971-6.

21. Mitsuyama K, Matsumoto S, Rose-John S, Suzuki A, Hara T, Tomiyasu N, Handa K, Tsuruta O, Funabashi H, Scheller J, Toyonaga A, Sata M. STAT3 activation via interleukin 6 trans-signalling contributes to ileitis in SAMP1/Yit mice. Gut. 2006;55(9):1263-9. Epub 2006 May 8.

22. Finotto S, Eigenbrod T, Karwot R, Boross I, Doganci A, Ito H, Nishimoto N, Yoshizaki K, Kishimoto T, Rose-John S, Galle PR, Neurath MF. Local blockade of IL-6R signaling induces lung CD4 ${ }^{+} \mathrm{T}$ cell apoptosis in a murine model of asthma via regulatory T cells. Int Immunol. 2007;19(6):685-93.

23. Richards PJ, Nowell MA, Horiuchi S, McLoughlin RM, Fielding CA, Grau S, Yamamoto N, Ehrmann M, Rose-John S, Williams AS, Topley N, Jones SA. Functional characterization of a soluble gp130 isoform and its therapeutic capacity in an experimental model of inflammatory arthritis. Arthritis Rheum. 2006;54(5):1662-72.

24. Yamamoto M, Yoshizaki $K$, Kishimoto T, Ito H. IL-6 is required for the development of Th1 cell-mediated murine colitis. J Immunol. 2000;164(9):4878-82.

25. Matsumoto S, Hara T, Mitsuyama K, Yamamoto M, Tsuruta O, Sata M, Scheller J, Rose-John S, Kado S, Takada T. Essential roles of IL-6 transsignaling in colonic epithelial cells, induced by the IL-6/soluble-IL-6 receptor derived from lamina propria macrophages, on the development of colitisassociated premalignant cancer in a murine model. J Immunol. 2010;184:1543-51.

26. Takai A, Marusawa H, Minaki Y, Watanabe T, Nakase H, Kinoshita K, Tsujimoto G, Chiba T. Targeting activation-induced cytidine deaminase prevents colon cancer development despite persistent colonic inflammation. Oncogene. 2011;31(13):1733-42.
27. Mitsuyama K, Matsumoto S, Yamasaki H, Masuda J, Kuwaki K, Takedatsu H, Nagaoka M, Andoh A, Tsuruta O, Sata M Beneficial effects of lactobacillus casei in ulcerative colitis:a pilot study. J Clin Biochem Nutr. 2008;43(1):78-81.

28. Ishikawa H, Akedo I, Otani T, Suzuki T, Nakamura T, Takeyama I, Ishiguro S, Miyaoka E, Sobue T, Kakizoe T. Randomized trial of dietary fiber and Lactobacillus casei administration for prevention of colorectal tumors. Int J Cancer. 2005;116(5):762-7.

29. Ishikawa H, Matsumoto S, Ohashi Y, Imaoka A, Setoyama H, Umesaki Y, Tanaka R, Otani T. Beneficial effects of probiotic bifidobacterium and galacto-oligosaccharide in patients with ulcerative colitis: a randomized controlled study. Digestion. 2011:84(2):128-33.

30. Matsumoto S, Hara T, Nagaoka M, Mike A, Mitsuyama K, Sako T, Yamamoto M, Kado S, Takada T. A component of polysaccharide peptidoglycan complex on Lactobacillus induced an improvement of murine model of inflammatory bowel disease and colitis-associated cancer. Immunology. 2009;128(1 Suppl):e170-80.

\section{Submit your next manuscript to BioMed Central and we will help you at every step:}

- We accept pre-submission inquiries

- Our selector tool helps you to find the most relevant journal

- We provide round the clock customer support

- Convenient online submission

- Thorough peer review

- Inclusion in PubMed and all major indexing services

- Maximum visibility for your research

Submit your manuscript at www.biomedcentral.com/submit 